\title{
Influência da infra-estrutura de transporte sobre a competitividade da soja mato-grossense ${ }^{1}$ \\ Influence of infrastructure of transportation on the competitiveness of Mato Grosso State soybean
}

\author{
Celso Correia de Souza ${ }^{2}$ \\ Cirineu Busanelo 3 \\ Edison Rubens Arrabal Arias 4 \\ J osé Francisco dos Reis Neto 5
}

\begin{abstract}
Resumo: A eficiência dos produtores de soja mato-grossense não é suficiente para garantir competitividade no mercado externo. Para garantir essa eficiência é necessária que se tenha à disposição uma eficiente infra-estrutura de transporte que permita que os insumos cheguem com fretes razoáveis e permita, principalmente, o escoamento do grão produzido sem que se perca a vantagem competitiva perante os concorrentes do mercado externo dessa commodity. O objetivo deste trabalho foi verificar a redução possível de custos com a utilização de rotas alternativas para o escoamento da soja produzida em Mato Grosso, visando ao mercado externo. Para a realização deste trabalho foram levantados valores médios dos fretes dos três principais modais de transporte (rodoviário, ferroviário e hidroviário) e as distâncias entre as regiões produtoras, os terminais intermodais e os portos brasileiros. Verificou-se ser possível economizar aproximadamente US\$ 67.75 por tonelada de soja exportada com a melhoria da infra-estrutura desses meios de transporte.
\end{abstract}

Palavras-chave: Produção de soja; transporte de soja; hidrovias mato-grossenses; planejamento regional; planejamento e políticas públicas.

\begin{abstract}
Mato Grosso soybean producers efficiency has not been enough to warrant competitiveness in the foreign market. In order to warrant such efficiency it is necessary to have a sufficient infrastructure of transportation available, as to allow input at reasonable freight costs and, mainly, to allow produced grain being transported without loosing competitive advantage over foreign competitor markets for that commodity. The objective of this research was to verify a possible cost reduction by using alternate routes to ship soybeans produced in Mato Grosso State, seeking foreign markets. In order to have this research done average freight costs have been raised at the three main modal transportation services (roads, railroad and waterway transportation) and distances among producing regions, inter-modal terminals and the Brazilian ports. It has been concluded that US\$ 67.75 per tone of exported soybeans would be saved by improving infrastructure of such transportation means.
\end{abstract}

Key Words: Soybeans production, soybeans transportation, Mato Grosso State waterway, regional planning, planning and public policy.

J EL: R23

\footnotetext{
${ }^{1}$ Artigo recebido em junho de 2010 e aprovado em outubro de 2010.

2 Graduado em Matemática. Mestrae em Matemática Aplicada. Doutor em Engenharia Elétrica. Professor do Mestrado em Produção e Gestão Agroindustrial da Universidade Anhanguera Uniderp. E-mail: csouza939@gmail.com

3 Graduado em Matemática. Mestre em Produção e Gestão Agroindustrial. Professor da Universidade Unicem de Primavera do Leste. E-mail: cirineubusanello@terra.com.br

${ }^{4}$ Graduado em Agronomia. Mestre e Doutor em Agronomia. Professor do Mestrado em Produção e Gestão Agroindustrial da Universidade Anhanguera Uniderp. E-mail: edisonarias@pop.com.br

${ }^{5}$ Graduado em Engenharia Elétrica. Mestre e Doutor em Administração. Professor do Curso de Administração da Universidade Anhanguera Uniderp. E-mail: jfreisneto@terra.com.br
} 


\section{Introdução}

Competitividade é crucial em tempos de mercados globalizados. Com a abertura comercial do Brasil, a formação e consolidação de blocos econômicos, em meados das décadas de 1980 e 1990, a globalização se fez mais presente na economia do país, tornando cada vez mais intenso o fluxo internacional de informações, tecnologias, serviços e, principalmente, mercadorias. Em países com economias fechadas ou parcialmente abertas, os agricultores contam com a proteção do Estado e, em muitos casos, também contam com subsídios agrícolas que acabam compensando sua ineficiência. Em economias abertas, baseadas nas interdependências econômicas, que se caracterizam pelo livre acesso a bens e serviços provenientes de países estrangeiros, a competitividade é avaliada pela capacidade de crescer superando os maiores concorrentes internacionais.

O setor produtivo brasileiro enfrenta, além da disputa com o mercado externo, os gargalos internos, especialmente no setor de transporte. O Brasil fez a opção pelo modal rodoviário que possui o segundo maior valor de frete entre todos os modais de transporte, sendo inferior apenas ao valor do frete aéreo. Essa opção levou a malha ferroviária ao esquecimento (mesmo apresentando um valor de frete bem menor que o modal rodoviário), sendo hoje praticamente a mesma extensão da década de 1930, com um agravante: vários trechos estão intransitáveis para o transporte de cargas agrícolas. O modal hidroviário, que apresenta um frete bem mais barato que o ferroviário, praticamente não teve investimentos. Se não bastasse a escolha pelo modal rodoviário, o país não realiza manutenção periódica de suas estradas, sendo que, atualmente, mais da metade das rodovias pavimentadas encontram-se em péssimas condições de trânsito, fazendo com que os custos dos fretes aumentem ainda mais.

Esta pesquisa teve como objetivo analisar e fazer um diagnóstico da infraestrutura de transporte que atende o Estado de Mato Grosso, apontando deficiências, ao mesmo tempo em que propõe soluções para o escoamento da produção de soja do Estado. Como objetivos específicos: levantar os principais modais de transporte atualmente utilizados para o escoamento da produção de soja do Mato Grosso; analisar rotas alternativas para o escoamento da soja destinada ao mercado externo e; avaliar o possível incremento na receita e lucratividade do produtor de soja com o uso de rotas alternativas de escoamento das safras.

\section{Modais de Transporte em Mato Grosso}

Na década de 1970, os governos militares incentivaram a ocupação de regiões que eram consideradas vazios demográficos, principalmente, o Norte e Centro-Oeste do Brasil, sob o lema "Ocupar a Amazônia para não entregar". Houve um fluxo migratório intenso de lavradores para essas regiões oriundas, principalmente, do Sul do país, em especial, do Rio Grande do Sul. Esse fluxo migratório ainda continua, porém, agora, não são apenas lavradores que chegam em busca da terra prometida, mas também profissionais formados nas mais diversas áreas do conhecimento humano (GAMBOA, 2005).

Inicialmente, duvidou-se de que as terras nas quais predominava o cerrado poderiam prestar para a agricultura, a julgar pela aparência frágil da vegetação e solo bastante arenoso. Hoje, a região Centro-Oeste desponta como grande 
produtora de grãos, algodão, cana-de-açúcar e gado de corte, entre outros produtos agropecuários. Também, experimenta uma considerável industrialização, especialmente, ligada ao setor agropecuário (BERNARDES, 2004; GAMBOA, 2005).

O aumento da produção e da produtividade vem andando a "passos largos", enquanto a infra-estrutura necessária para dar suporte a esse incremento no volume das safras, anda a "passos lentos". Isso tem sido um obstáculo no caminho do desenvolvimento do Estado de Mato Grosso, fazendo com que o agronegócio perca em competitividade, o agricultor perca receita e diminua a lucratividade e, em conseqüência, o Estado, os municípios e a União percam em arrecadação, ou seja, uma corrente de perdas (MELO, 2004; WEDEKIN, 2004; RIVA NETO, 2004).

Segundo o Anuário Estatístico de Mato Grosso de 2002, dos 24.472,5 km de estradas estaduais e federais do Estado, apenas 4.605,5 km são pavimentados. Se isso não fosse suficiente, boa parte das rodovias pavimentadas fica quase intransitável, especialmente, no fim da estação chuvosa por causa do tráfego intenso e da má qualidade da pavimentação (SEPLAN-MT, 2002).

Para viabilizar a atividade e tornar o produto agrícola mato-grossense mais competitivo e ainda ampliar a área de plantio, alguns investimentos em infraestrutura são fundamentais e urgentes: asfaltamento da BR-163 até Belém, ampliação das hidrovias dos rios Madeira-Mamoré-Guaporé, Teles PiresTapajós e das Mortes-Araguaia-Tocantins e a ampliação das ferrovias Ferronorte e da Companhia Vale do Rio Doce (CVRD), pois constituem as principais alternativas para o escoamento da produção agrícola, capazes de dar novo fôlego ao agronegócio mato-grossense e de provocar uma redução significativa dos custos de produção e de transporte da soja mato-grossense (RIBEIRO, 2005). Além dessas obras, não se pode esquecer de melhorar, ampliar e pavimentar as rodovias existentes e, se necessário, construir novas rodovias para facilitar o acesso aos terminais de carga e descarga. Também são necessários investimentos em terminais de carga e descarga (SEPLAN-MT, 2002).

\section{Material e Métodos}

Para o desenvolvimento do presente trabalho foram feitas consultas bibliográficas, visitas à Secretaria de Infra-Estrutura de Mato Grosso (SINFRA), à Secretaria de Estado de Desenvolvimento Rural (SEDER), ao Instituto Brasileiro de Geografia e Estatística (IBGE), em Cuiabá, MT, e às empresas transportadoras e exportadoras de soja, para a coleta de dados e informações não estruturadas que apoiaram a evolução e a análise deste estudo.

Foram estabelecidas como cidades pólos: Água Boa (localizada no leste do MT), Sapezal (no oeste do MT) e Sorriso (no centro do MT) pelas suas localizações geográficas e pelas suas produções - ou potenciais de produção - de soja. Também, a escolha por essas cidades-pólos se deu pelo fato de que os valores obtidos para o escoamento da soja produzida nesses pólos podem ser generalizados para as cidades próximas, uma vez que suas localizações estão em pontos mais ou menos centralizados em suas microrregiões.

Na presente pesquisa são comparados os custos de escoamento das safras de soja mato-grossense para o mercado externo, entre as rotas tradicionais e rotas 
alternativas. Considerou-se o início das rotas as regiões produtoras de soja de Mato Grosso, e os destinos considerados são os portos de Roterdã, na Holanda, e Xangai, na China, por serem destino de praticamente $100 \%$ das exportações de soja mato-grossense. Para estabelecer comparações, foram consideradas como rotas tradicionais a rodoviária até o Porto de Paranaguá, a ferroviária até o porto de Santos, SP, e a que utiliza a rodovia até Porto Velho, RO, e de Porto Velho até Itacoatiara, AM, utilizando a hidrovia do rio Madeira.

As rotas alternativas consideradas são a rodovia BR-163 até Santarém, PA, a hidrovia dos rios das Mortes-Araguaia-Tocantins, dos rios Teles Pires-Tapajós e dos rios Guaporé-Mamoré-Madeira, saindo por Itacoatiara, e a dos rios Guaporé-Mamoré-Beni-Madre de Dios, navegando até Puerto Maldonado, no Peru, seguindo de caminhão - também há a alternativa de fazer parte do percurso de trem quando a opção for pelo porto fluvial de Matarani, Peru - até os portos peruanos no Oceano Pacífico, especialmente, o porto de San Juan de Marconda que, embora, atualmente, não apresente a infra-estrutura necessária para movimentar grandes volumes de cargas, há profundidade que permite o atraque de navios de grande porte (capacidade de 120 mil toneladas), e há intenção do governo peruano e, também, da iniciativa privada de fazer os investimentos necessários para dotar o porto de infra-estrutura necessária que permita movimentar grandes volumes de cargas, visando à integração Brasil-Peru.

Para efeito dos cálculos do frete marítimo, foram considerados dois tipos de navios - Panamax e Post-Panamax - de acordo com as condições oferecidas pelo porto de embarque, visto que os fretes variam significativamente entre os tipos de navios disponíveis para o transporte de granéis sólidos. O Quadro 1 apresenta os valores médios dos fretes dos modais rodoviário, ferroviário, hidroviário e marítimo, em dólar.

Quadro 1. Custo médio dos fretes rodoviário, ferroviário, hidroviário e marítimo, em dólar

\begin{tabular}{|c|c|c|}
\hline \multicolumn{2}{|c|}{ MODAIS } & FRETE MÉDIO US\$/ 1000TKU \\
\hline \multicolumn{2}{|c|}{ Rodoviário } & 32.00 \\
\hline \multicolumn{2}{|c|}{ Ferroviário } & 16.00 \\
\hline \multicolumn{2}{|c|}{ Hidroviário } & 8.00 \\
\hline \multirow{3}{*}{$\begin{array}{c}\text { Marítimo } \\
\text { Transoceânico }\end{array}$} & Handy Size (30000 t) & 2.00 \\
\hline & Panamax (50000 t) & 1.50 \\
\hline & Cape Size (120000 t) & 0.50 \\
\hline
\end{tabular}

Fonte: Pavan, 2006.

A Figura 1 mostra o mapa do Estado de Mato Grosso e suas principais rodovias, ferrovia Ferronorte e a hidrovia do rio Paraguai, bem como possíveis traçados de ferrovias e rios que comportam hidrovias sugeridas a serem implantadas.

6 Tonelada quilômetro útil. 
Figura 1 - Estado de Mato Grosso e suas principais rodovias, ferrovia, hidrovia e traçados de novas rodovias e ferrovias.

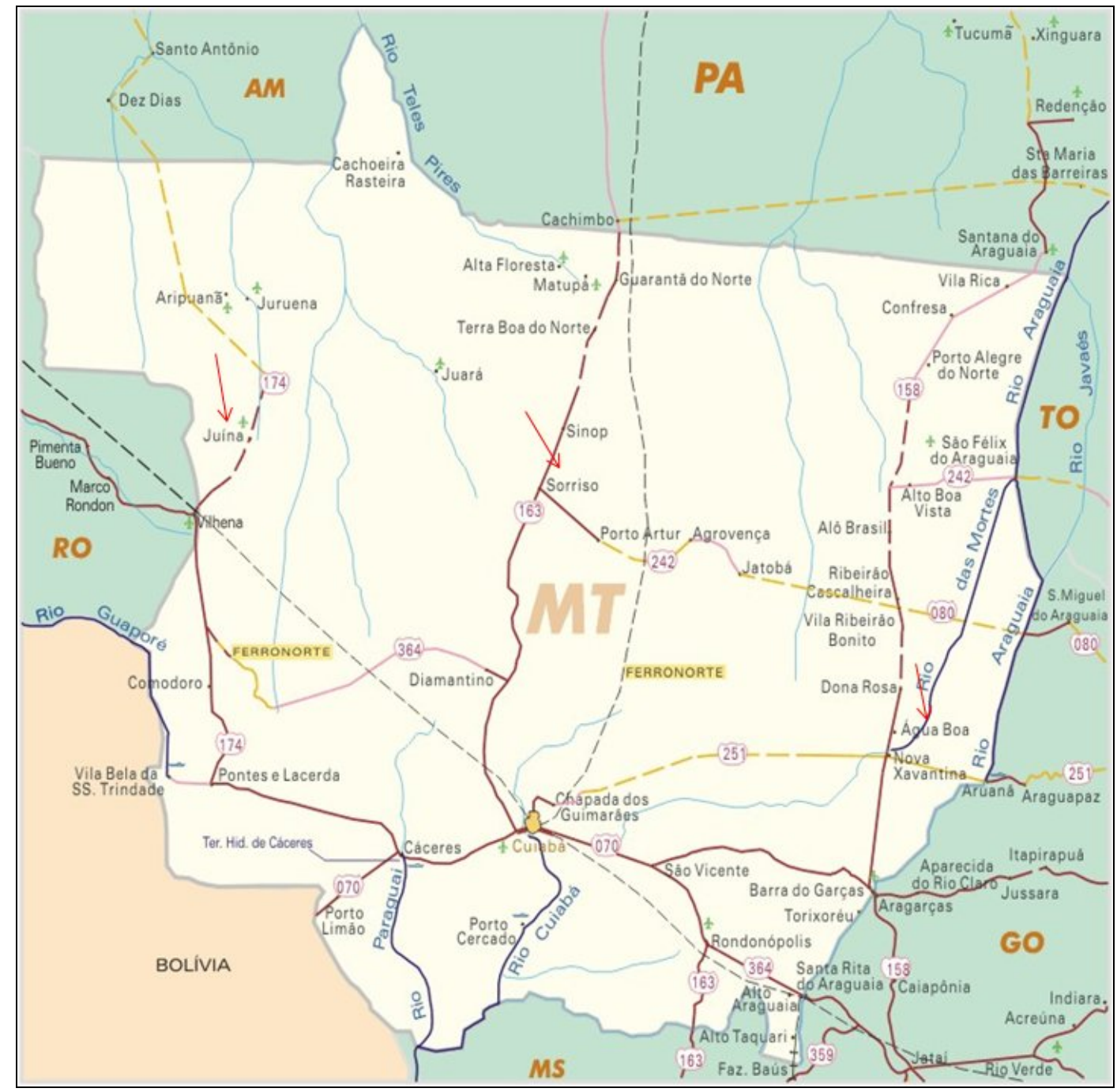

Fonte: Mato Grosso (2005).

\section{Resultados e Discussão}

Inicialmente, foi feita uma análise dos principais modais de transporte do Estado de Mato Grosso, tanto daqueles que se encontram em pleno funcionamento, quanto daqueles em construção ou em planejamento. Após, comparou-se o escoamento da soja de Mato Grosso até os principais pólos mundiais de distribuição dessa commodity, utilizando a infra-estrutura de transporte hoje implantada no Brasil, particularmente, nesse Estado, com aquela infra-estrutura planejada ou idealizada. 


\subsection{Hidrovia do Rio Madeira}

A hidrovia do rio Madeira está em operação no trecho entre Porto Velho, RO, e Itacoatiara, AM, desde 1997, transportando, principalmente, soja produzida na região da Chapada dos Parecis, no Mato Grosso. Essa hidrovia apresenta uma vantagem significativa em relação ao antigo caminho que a soja percorria até ser exportada pelo porto de Paranaguá, PR, ou Santos, SP. Segundo Rocha (2004), o presidente do Grupo Maggi, que opera a hidrovia, afirma que esse percurso proporciona redução de US\$25.00 por tonelada transportada em relação ao transporte rodoviário. Somando-se esse ganho à economia do frete marítimo com a saída pelo rio Amazonas, pode-se afirmar que os produtores de soja da região de influência dessa hidrovia podem receber, no mínimo, o mesmo valor por tonelada que os produtores do Estado do Paraná, isto é, um incremento de US\$ 33.33 por tonelada do produto.

A construção das usinas hidrelétricas de Jirau e de Santo Antônio permitirá estender o trecho navegável do rio Madeira até a foz do rio Beni, Bolívia. Caso sejam superados os pontos críticos na região de Guajará-Mirim, RO poderá ocorrer a interligação com os rios Mamoré e Guaporé e, assim, a Hidrovia MadeiraMamoré-Guaporé teria uma extensão de mais de $3.000 \mathrm{~km}$. Esse estirão ligaria as cidades de Vila Bela da Santíssima Trindade (antiga Cidade de Mato Grosso), MT, e o Porto de Itacoatiara, AM, permitindo ainda a integração hidroviária com a Bolívia e o Peru, favorecendo a integração desses países com o Brasil e intensificando as relações comerciais entre eles e os países sul-americanos (ANA, 2005).

A construção das usinas hidrelétricas do rio Madeira, com a de uma usina no rio Madre de Dios na altura da Cachoeira Espranza, em território boliviano, permitirá a navegação até Puerto Maldonado, no Peru, viabilizando a sonhada saída para o Oceano Pacífico pelo Puerto San J uan de Marcona, Puerto Matarani ou Puerto Ilomuito, o caminho para a Ásia (ELETROBRÁS, 2005).

A distância do porto de Paranaguá ao porto de Xangai é de $25.004 \mathrm{~km}$ e de Puerto San Juan de Marcona a Xangai é de $17.160 \mathrm{~km}$, que permite encurtar a distância em mais de $7.800 \mathrm{~km}$. O trecho entre Puerto Maldonado e Puerto San Juan de Marcona é ligado por rodovia, com uma distância de aproximadamente $1.330 \mathrm{~km}$, observando que de Puerto Maldonado até Urcos, a rodovia não é pavimentada - aproximadamente $600 \mathrm{~km}$. A ligação de Puerto Maldonado a Puerto Matarani e Puerto Ilo, também, é feita por transporte terrestre rodoviário, na qual boa parte da rota é coincidente com a rota para Puerto San J uan de Marcona, porém o trecho de rodovia não pavimentada é superior em cerca de 80 $\mathrm{km}$. As distâncias de Puerto Maldonado ao Puerto Matarani e ao Puerto Ilo são, respectivamente, $1.100 \mathrm{~km}$ e $1.150 \mathrm{~km}$ (ELETROBRÁS, 2005).

Na cidade de Cusco, Peru, é possível fazer o transbordo da carga para seguir viagem de trem até o Puerto de Matarani, porém esse porto não tem profundidade suficiente para atracar navios de grande porte - navios menores apresentam fretes maiores por tonelada. O trecho rodoviário entre Puerto Maldonado e Puerto de Matarani é mais curto em $230 \mathrm{~km}$ em relação à Puerto Maldonado e Puerto San Juan de Marcona, porém apresenta cerca de $80 \mathrm{~km}$ a mais de rodovias sem pavimento (ELETROBRÁS, 2005).

A integração da infra-estrutura com os países vizinhos ao Brasil é fundamental não somente para buscar a saída pelo Pacífico, mas para acessar os 
mercados dos países do Centro-Oeste e dos países sul-americanos com uma população de 40 milhões de habitantes, distribuídos em cinco milhões de km², dos quais se podem importar sal, fertilizantes, pescado e metais, e em contrapartida podem-se exportar grãos, fibras, madeira e carne, produtos e matéria-prima que atualmente são importados, principalmente, dos Estados Unidos (RIBEIRO, 2006).

\subsection{Hidrovia dos Rios Araguaia-Tocantins}

A hidrovia dos rios Tocantins-Araguaia-das Mortes - que está sob a jurisdição da Administração das Hidrovias do Tocantins e Araguaia (AHITAR), beneficiará cinco Estados, Mato Grosso, Goiás, Tocantins, Pará e Maranhão, e tornará viável economicamente o cultivo de novos alimentos em extensas áreas não cultivadas desses Estados (AHITAR, 2005a).

Estudos da Agência Nacional de Águas (ANA) mostram que essa hidrovia influenciará uma área agricultável de 35 milhões de hectares e com um potencial de mais de 100 milhões de toneladas/ano de grãos. O produto dessa região se tornará muito competitivo nos mercados interno e, principalmente, externo. A extensão futura dessa hidrovia poderá alcançar mais de $3.000 \mathrm{~km}$ nesses três rios, ligando o Brasil Central aos portos de Belém e Vila do Conde, no Pará, e pela ferrovia dos Carajás aos portos de Itaqui e Ponta da Madeira, no Maranhão (BRASIL, 2005).

Algumas intervenções no rio Araguaia são necessárias para permitir a navegação, especialmente, no período das águas baixas que vai de julho até outubro. De acordo com um levantamento feito pela ANA, as principais intervenções são as construções de duas barragens com eclusas, uma nas corredeiras do rio Santa Isabel e outra, em Araguanã, TO. Também, podem ser necessárias dragagens de alguns pontos de menor profundidade e derrocamento de alguns pedrais, tornando o rio navegável o ano todo (ANA, 2005).

Quando a hidrovia dos rios das Mortes-Tocantins-Araguaia for navegável em toda sua extensão, a economia com frete em relação às rotas tradicionais será bastante significativa. No Estado de Mato Grosso, as regiões leste e nordeste seriam as mais beneficiadas. Estudos feitos por técnicos da Companhia Vale do Rio Doce mostram que o pólo potencial de soja do sul do Pará e norte do Mato Grosso teria um frete de US $\$ 44.50$ por tonelada transportada, menor quando comparado ao pólo de Diamantino, MT, em condições atuais.

Segundo estimativa do Ministério da Agricultura, Pecuária e Desenvolvimento, com o desenvolvimento da agricultura na região da hidrovia Araguaia-Tocantins, seria possível criar 850 mil empregos, estimando em 350 mil diretos. Isso porque a hidrovia vai estimular a incorporação de quase 30 milhões de hectares ao sistema produtivo, com um potencial para produzir 73 milhões de toneladas de grãos, principalmente, soja, milho e arroz (AHITAR, 2005a).

A região dos Cerrados do Centro-Oeste é apontada como uma das melhores do mundo para a produção de grãos por causa da incidência da luz solar, do relevo, da água e do solo. Se for capaz de juntar essa condição favorável de produção com uma aceitável logística de transporte no escoamento das safras agrícolas, o país terá condições de competir com seus maiores concorrentes. Somada à intensidade da luz solar, outros fatores favoráveis, como topografia, solo e água, contribuem 
para que a região dos Cerrados seja considerada como uma das mais favoráveis do planeta para a produção de alimentos (ECONOMIA AGRICULTURA, 2005).

No rio das Mortes já há uma infra-estrutura para embarque e desembarque na travessia da rodovia MT-326, no município de Nova Nazaré, MT, que atende uma região estratégica com potencial importante de produção de grãos, com acesso facilitado pelos municípios de Água Boa, Canarana e Nova Xavantina, todos no Estado de Mato Grosso e outras regiões produtoras de grãos. Atualmente, essas instalações encontram-se desativadas em função da proibição da navegação nos rios das Mortes e Araguaia (AHITAR, 2005b).

\subsection{Hidrovia dos Rios Teles Pires-Tapajós}

A hidrovia dos rios Teles Pires-Tapajós encurtará o caminho da soja produzida nas regiões central e norte do Mato Grosso e região central do Pará ao mercado externo, saindo pelo rio Amazonas. Essa hidrovia pode não ser apenas uma alternativa que reduzirá o custo de escoamento da soja, mas também ser o caminho que viabilizará a produção na região de sua abrangência, especialmente no Estado do Pará, incorporando milhares de hectares ao sistema produtivo de alimentos, trazendo desenvolvimento à região. A hidrovia, além de proporcionar inúmeros benefícios regionais, será fundamental na consolidação da grande infraestrutura para tornar o Estado de Mato Grosso e parte da região Centro-Oeste nos "celeiros mundiais" da produção de grãos. O prazo de execução das obras necessárias à consolidação da via navegável e implantação da navegação comercial é de cerca de 36 meses (ANA, 2005).

O rio Tapajós é navegável desde o porto de Santarém, PA, na sua foz até as corredeiras de São Luís do Tapajós, na cidade da Itaituba, PA. Para superar essa corredeira está prevista a construção de um canal com eclusa. Também será necessário o derrocamento de pedrais. Esse conjunto de medidas, além da dragagem de alguns pontos de menor profundidade, tornará o rio navegável até a Cachoeira Rasteira na divisa dos Estados de Mato Grosso e Pará, no rio Teles Pires. Os estudos realizados demonstraram que o custo médio de transporte pela hidrovia Teles Pires-Tapajós, entre a região de Cachoeira Rasteira, MT, e Santarém, PA, é de cerca de US\$6.00/t, permitindo projetar uma economia acumulada no custo de transporte equivalente a US\$ 93,385,290.00 nos primeiros seis anos de operação da via. Considerando-se que a estimativa global de custos para tornar os rios Tapajós e Teles Pires navegáveis, da sua foz até a região de cachoeira Rasteira $(1.043 \mathrm{~km})$, é da ordem R\$ 87.377.502,00. Desta forma, a economia de fretes gerada será suficiente para pagar integralmente o custo de implantação da hidrovia nesse período, o que atesta a viabilidade econômica do empreendimento (AHITAR, 2005b).

A utilização da hidrovia Teles Pires-Tapajós trará uma redução de cerca de US\$ 36.40/t no frete para escoar a soja produzida nos municípios do norte do Estado de Mato Grosso, em comparação à opção rodoviária para os portos de Santos, SP, ou Paranaguá, PR, representando uma economia de cerca de $50 \%$ do frete. Pelo menos boa parte dessa economia poderá se transformar em aumento da rentabilidade e lucratividade para o produtor. 


\subsection{Rodovia BR-163}

A construção do trecho Cuiabá-Santarém, da BR-163, teve início em 1971 e concluído em 1976. Entre outros tantos desafios enfrentados, a malária foi uma ameaça constante que obrigou substituições freqüentes de operários, também provocando algumas mortes. Superando as adversidades, a construção da rodovia avançou, em média, $2 \mathrm{~km}$ por dia (GOMES, 2004b)

A pavimentação da BR-163 até Santarém, PA, permitiria o surgimento de uma nova rota para o mercado inter-regional do Mato Grosso com o Nordeste, para onde são escoados produtos agrícolas, sobretudo soja, milho e arroz, e de onde se importam sal, insumos agrícolas, química fina, derivados de petróleo, manufaturados, medicamentos humanos e roupa por meio do porto de Santarém. Isto fará com que o milho produzido no norte do Mato Grosso ganhe competitividade para concorrer com o milho importado principalmente da Argentina. Também o porto de Santarém, no rio Tapajós, tem grande vantagem sobre os portos de Santos e Paranaguá quando o assunto é distância aos grandes centros importadores da Europa e Ásia. Comparando com o escoamento por com Paranaguá, encurta o trajeto para Tóquio, Japão, em $4.100 \mathrm{~km}$, e para Roterdã, Holanda, em $4.200 \mathrm{~km}$. O mesmo se aplica em relação a Santos: $3.587 \mathrm{~km}$ a menos para a capital japonesa, e $3.721 \mathrm{~km}$ a menos para a cidade holandesa (GOMES, 2004b).

É evidente que encurtar a distância entre os portos não é a única vantagem que a BR- 163 pode oferecer para os produtores de soja da área de sua abrangência do norte do Mato Grosso. Além do menor custo para colocar a soja no porto em função da menor distância entre este e a região produtora, Santarém fica mais próximo dos centros consumidores de alimentos, que estão localizados no hemisfério Norte, do que Santos ou Paranaguá. Isto significa que a distância entre o porto de origem e o de destino também será menor. Empresários da região de Alta Floresta, no Mato Grosso, já concluíram que o custo de frete do escoamento da soja, a partir da região central do seu Estado, no município de Sorriso, em direção ao porto de Roterdã, na Holanda, pelo porto de Santarém e passando pela BR-163, teria um diferencial entre US\$ 33.00/t e US\$ 37.50/t transportada em relação ao escoamento pelos portos de Paranaguá e Santos (GOMES, 2004a).

\subsection{Rodovia BR-158}

Foi fechado o acordo entre o governo do Estado do Mato Grosso e o Governo Federal para a pavimentação de um trecho de $141 \mathrm{~km}$ dos $417 \mathrm{~km}$ que faltam ser pavimentados da BR-158, trecho esse localizado entre Ribeirão Cascalheira e Estrela do Araguaia, no entroncamento com a BR-242 (GOMES, 2004d).

Outro entrave para o desenvolvimento da agricultura nessa região era a distância elevada para trazer o calcário indispensável na correção da acidez do solo. No ano de 2003, a Companhia Mato-Grossense de Mineração detectou a presença desse mineral em alguns pontos da região, fez mapeamento geológico detalhado de uma área de $477 \mathrm{~km}^{2}$ na calha do rio Tapirapé, em Porto Alegre do Norte, e colheu amostras para análises químicas. No ano seguinte foi feito levantamento de depósitos economicamente viáveis para, em seguida, terceirizar a exploração pela iniciativa privada (GOMES, 2004d). 
Outra alternativa interessante é o corredor multimodal composto da hidrovia Araguaia - das Mortes, das ferrovias Norte-Sul e Carajás e do porto de Ponta da Madeira, MA. Dependendo da região produtora da qual será exportada, a soja pode ser embarcada em pontos diferentes dos rios Araguaia ou das Mortes e transportada até Couto Magalhães ou Xambioá, no Mato Grosso. Daí seguindo de caminhão até Porto Franco e embarcando na ferrovia Norte-Sul, operada pela Companhia Vale do Rio Doce, que se liga à ferrovia Carajás, de propriedade da CVRD, chegando ao porto Ponta da Madeira, no Maranhão (PAULA; FAVERET FILHO, 2005)

\subsection{Ferrovia Ferronorte}

Em 1999, foi inaugurado o primeiro trecho da Ferronorte, com $421 \mathrm{~km}$, ligando Aparecida do Taboado, MS, a Alto Taquari, MT. Em abril de 2002 foram inaugurados mais $90 \mathrm{~km}$ de linha, ligando Alto Taquari a Alto Araguaia, em Mato Grosso, totalizando $511 \mathrm{~km}$. O próximo passo é atingir Rondonópolis, MT, seguindo depois para Cuiabá, MT (GOMES, 2004a; GOMES, 2004d). Estava prevista a ferrovia da Ferronorte até Cuiabá, com um ramal chegando a Porto Velho, RO, e outro ligando à Belém, PA, porém não passou de Alto Taquari (GOMES, 2004d).

\section{Comparação entre os Valores dos Fretes das Rotas Tradicionais e Alternativas para Exportação}

\subsection{Pólo de Água Boa, MT}

Para a soja produzida no pólo de Água Boa, MT, atualmente as rotas principais de exportação são por rodovia até Paranaguá ou pela opção rodoferroviária, seguindo por rodovia até Alto Taquari, MT, e, posteriormente, de trem até Santos, SP, ou Paranaguá, PR. O Quadro 2 apresenta as opções de transporte da soja produzida na região de Água Boa, com as alternativas atuais e previstas para o seu escoamento até os centros de Roterdã, Holanda, e Xangai, China. Qualquer que seja a opção, o navio a ser utilizado será o Panamax em função de os portos de Santos e Paranaguá não permitirem o atraque de navios Post-Panamax.

Mesmo ainda não operando, optou-se em apresentar a alternativa de transporte hidroviário utilizando os rios das Mortes-Araguaia-Tocantins até o porto de Belém, PA, e daí até Roterdã ou Xangai.

Comparando-se o custo do frete até Roterdã, via Paranaguá, a opção pela hidrovia dos rios das Mortes-Araguaia-Tocantins traria uma economia de US\$ 47.40 (US\$ 82.00 - US\$ 34.60)/t de soja embarcada. Fazendo-se a comparação dos fretes até Roterdã, por Santos e pela hidrovia, a economia seria de US\$19.31 (US\$ 53.91 - US\$ 34.60)/t. Quando o destino considerado for Xangai, saindo por Paranaguá, o frete fica US\$ 50.95 (US\$ 100.45 - US\$ 53.50)/t mais caro do que sair pela hidrovia. Comparando-se com o frete até Xangai via Santos, a opção pela hidrovia fica US\$19.11(US\$ 72.61 - US\$ 53.50)/t mais barata. 
Quadro 2 - Custos de transporte multimodal da soja de Água Boa, MT à Roterdã ou Xangai

\begin{tabular}{|c|c|c|c|c|c|}
\hline ORIGEM & RODOVIÁRIO & FERROVIÁRIO & HIDROVIÁRIO & MARÍTIMO & DESTINO \\
\hline \multirow[t]{8}{*}{$\begin{array}{c}\text { Água Boa, } \\
\text { MT }\end{array}$} & $\begin{array}{l}\text { Paranaguá } \\
\text { US\$ } 64.00\end{array}$ & & & $\begin{array}{c}\text { Roterdã } \\
\text { US\$ } 18.00\end{array}$ & $\begin{array}{c}\text { Roterdã } \\
\text { US\$ } 82.00\end{array}$ \\
\hline & $\begin{array}{l}\text { Alto Taquari } \\
\text { US\$ } 13.76\end{array}$ & $\begin{array}{c}\text { Santos } \\
\text { US\$ } 22.40\end{array}$ & & $\begin{array}{c}\text { Roterdã } \\
\text { US\$ } 17.75\end{array}$ & $\begin{array}{c}\text { Roterdã } \\
\text { US\$ } 53.91\end{array}$ \\
\hline & $\begin{array}{c}\text { Rio das Mortes } \\
\text { US\$ } 4.00\end{array}$ & & $\begin{array}{c}\text { Belém } \\
\text { US\$ } 16.80\end{array}$ & $\begin{array}{c}\text { Roterdã } \\
\text { US\$ } 13.80\end{array}$ & $\begin{array}{c}\text { Roterdã } \\
\text { US\$ } 34.60\end{array}$ \\
\hline & $\begin{array}{l}\text { Paranaguá } \\
\text { US\$ } 64.00\end{array}$ & & & $\begin{array}{c}\text { Xangai } \\
\text { US\$ } 36.45\end{array}$ & $\begin{array}{c}\text { Xangai } \\
\text { US\$ } 100.45\end{array}$ \\
\hline & $\begin{array}{c}\text { Alto Taquari } \\
\text { US\$ } 13.76\end{array}$ & $\begin{array}{c}\text { Santos } \\
\text { US\$ } 22.40\end{array}$ & & $\begin{array}{c}\text { Xangai } \\
\text { US\$ } 36.45\end{array}$ & $\begin{array}{c}\text { Xangai } \\
\text { US\$ } 72.61\end{array}$ \\
\hline & $\begin{array}{c}\text { Rio das Mortes } \\
\text { US } \$ 4.00\end{array}$ & & $\begin{array}{c}\text { Belém } \\
\text { US\$ } 16.80\end{array}$ & $\begin{array}{c}\text { Xangai } \\
\text { US\$ } 32.70\end{array}$ & $\begin{array}{c}\text { Xangai } \\
\text { US\$ 53.20 }\end{array}$ \\
\hline & $\begin{array}{c}\text { Rio das Mortes } \\
\text { US\$ } 4.00\end{array}$ & & $\begin{array}{c}\text { Porto Espadarte } \\
\text { US\$ } 17.92\end{array}$ & $\begin{array}{c}\text { Roterdã } \\
\text { US\$ } 4.49\end{array}$ & $\begin{array}{c}\text { Roterdã } \\
\text { US\$ } 26.41\end{array}$ \\
\hline & $\begin{array}{c}\text { Rio das Mortes } \\
\text { US } \$ 4.00\end{array}$ & & $\begin{array}{c}\text { Porto Espadarte } \\
\text { U\$ } 17.92\end{array}$ & $\begin{array}{c}\text { Xangai } \\
\text { US\$ } 10.78\end{array}$ & $\begin{array}{c}\text { Xangai } \\
\text { US\$ } 32.70\end{array}$ \\
\hline
\end{tabular}

Fonte: Resultados da Pesquisa.

Outra comparação foi realizada quando se considerou o projeto do porto do Espadarte, PA, que deverá ser construído na Ilha dos Guarás, na foz do rio Amazonas, no litoral paraense. Esse porto, com um calado de $25 \mathrm{~m}$, permitirá o atraque de navios de grande capacidade de carga (Post-Panamax) que reduzem muito o valor do frete marítimo. Para tal comparação basta acrescentar cerca de $140 \mathrm{~km}$ de hidrovia em relação aos portos de Belém e refazer os cálculos dos fretes hidroviários e marítimos. Para isso considera-se a hidrovia com cerca de $2.240 \mathrm{~km}$, cujo frete ficaria em torno de US\$ 17.92 por tonelada e a distância do porto do Espadarte a Roterdã é de $8.969 \mathrm{~km}$, cujo frete, em navios Post-Panamax, ficaria em US\$ 4.49/t. Somando-se o frete rodoviário e o hidroviário com o frete marítimo, custaria US\$26.41/t para levar uma tonelada de soja de Água Boa a Roterdã. Se comparado à opção de Paranaguá, trará uma economia de US\$ 55.59 (US\$ 82.00 - US\$ 26.41)/t.

Quando a comparação for com Santos, trará uma economia de US\$27.50 (US\$ 53.91 - US\$ 26.41)/ t. Quando o destino da soja for Xangai, cuja distância do porto do Espadarte é de $21.549 \mathrm{~km}$, o frete marítimo ficaria em US\$10.78, que, somado ao frete rodoviário de US\$ 4.00/t e hidroviário de US\$17.92/t, perfaz um total de US\$ 32.70/t. Em relação à rota por Paranaguá seriam economizados US\$ 67.75 (US\$ 100.45 - US\$ 32.70)/t e, em relação a Santos, a economia ficaria em US\$ 39.91(US\$ 72.61 - US\$ 32.70)/t.

\subsection{Pólo de Sorriso, MT}

Comparando os custos de exportação da soja do pólo de Sorriso, MT, para Roterdã, Holanda, fazendo-se uso da rodovia BR-163 com os custos para exportar por Paranaguá, PR, e Santos, SP, o uso dessa rodovia traria uma economia de US\$ 29.41 (US\$ 87.76 - US\$ 58.35)/t e US\$ 10.60 (US\$ 68.95 - US\$ 58.35)/t, respectivamente. O Quadro 3 apresenta o esquema de transporte multimodal da soja produzida em Sorriso, MT, até os portos de Roterdã ou Xangai. 
Quadro 3 - Custos de transporte multimodal da soja de Sorriso, MT, a Roterdã ou Xangai

\begin{tabular}{|c|c|c|c|c|c|}
\hline \multirow{11}{*}{$\begin{array}{c}\text { ORIGEM } \\
\text { Sorriso, } \\
\text { MT }\end{array}$} & RODOVIÁRIO & FERROVIÁRIO & HIDROVIÁRIO & MARÍTIMO & DESTINO \\
\hline & $\begin{array}{l}\text { Paranaguá } \\
\text { US\$ 69,76 }\end{array}$ & & & $\begin{array}{c}\text { Roterdã } \\
\text { US\$ } 18.00\end{array}$ & $\begin{array}{c}\text { Roterdã } \\
\text { US\$ } 87.76\end{array}$ \\
\hline & $\begin{array}{l}\text { Alto Taquari } \\
\text { US\$ } 28.80\end{array}$ & $\begin{array}{c}\text { Santos } \\
\text { US\$ 22 40 }\end{array}$ & & $\begin{array}{c}\text { Roterdã } \\
\text { US\$ } 1775\end{array}$ & $\begin{array}{c}\text { Roterdã } \\
\text { US\$ } 68.95\end{array}$ \\
\hline & $\begin{array}{c}\text { Santarém } \\
\text { US\$ } 43.20\end{array}$ & & & $\begin{array}{c}\text { Roterdã } \\
\text { US\$ } 15.15\end{array}$ & $\begin{array}{c}\text { Roterdã } \\
\text { US\$ 58.35 }\end{array}$ \\
\hline & $\begin{array}{c}\text { Cachoeira } \\
\text { Rasteira } \\
\text { US\$ } 11.20\end{array}$ & & $\begin{array}{l}\text { Santarém } \\
\text { US\$ } 8.40\end{array}$ & $\begin{array}{c}\text { Roterdã } \\
\text { US\$ } 15.15\end{array}$ & $\begin{array}{c}\text { Roterdã } \\
\text { US\$ } 34.75\end{array}$ \\
\hline & $\begin{array}{c}\text { Cachoeira } \\
\text { Rasteira } \\
\text { US\$ } 11.20\end{array}$ & & $\begin{array}{l}\text { Porto do Espadarte } \\
\text { US\$ } 16.96\end{array}$ & $\begin{array}{l}\text { Roterdã } \\
\text { US\$ } 4.49\end{array}$ & $\begin{array}{l}\text { Roterdã } \\
\text { US\$ } 32.65\end{array}$ \\
\hline & $\begin{array}{l}\text { Paranaguá } \\
\text { US\$ } 69.76\end{array}$ & & & $\begin{array}{c}\text { Xangai } \\
\text { US\$ } 36.45\end{array}$ & $\begin{array}{c}\text { Xangai } \\
\text { US\$ } 106.21\end{array}$ \\
\hline & $\begin{array}{l}\text { Alto Taquari } \\
\text { US\$ } 28.80\end{array}$ & $\begin{array}{c}\text { Santos } \\
\text { US } \$ 22.40 \\
\end{array}$ & & $\begin{array}{c}\text { Xangai } \\
\text { US\$ } 36.45\end{array}$ & $\begin{array}{c}\text { Xangai } \\
\text { US\$ 87.65 }\end{array}$ \\
\hline & $\begin{array}{c}\text { Santarém } \\
\text { US\$ } 43.20\end{array}$ & & & $\begin{array}{c}\text { Xangai } \\
\text { US\$ } 33.93\end{array}$ & $\begin{array}{c}\text { Xangai } \\
\text { US\$ } 77.13\end{array}$ \\
\hline & $\begin{array}{c}\text { Cachoeira } \\
\text { Rasteira } \\
\text { US\$ } 11.20\end{array}$ & & $\begin{array}{l}\text { Santarém } \\
\text { US\$ } 8.40\end{array}$ & $\begin{array}{c}\text { Xangai } \\
\text { US\$ } 33.93\end{array}$ & $\begin{array}{c}\text { Xangai } \\
\text { US\$ } 53.53\end{array}$ \\
\hline & $\begin{array}{c}\text { Cachoeira } \\
\text { Rasteira } \\
\text { US\$ } 11.20\end{array}$ & & $\begin{array}{l}\text { Porto do Espadarte } \\
\text { US\$ } 16.96\end{array}$ & $\begin{array}{c}\text { Xangai } \\
\text { US\$ } 10.78\end{array}$ & $\begin{array}{c}\text { Xangai } \\
\text { US\$ 38,94 }\end{array}$ \\
\hline
\end{tabular}

Fonte: Resultados da Pesquisa.

Considerando-se o trecho rodoviário até Cachoeira Rasteira, AM, o percurso pela hidrovia de Cachoeira Rasteira até Santarém, PA, e de Santarém até Roterdã, a economia ficaria em US\$ 53.01 (US\$ 87.76 - US\$ 34.75)/t se comparado com a opção por Paranaguá e US\$ 34.20 (US\$ 68.95 - US\$ 34.75)/t, se comparado com a opção por Santos, SP.

Quando a comparação é feita utilizando o trajeto rodoviário do pólo de Sorriso até Cachoeira Rasteira e de Cachoeira Rasteira até o porto do Espadarte, PA, o transporte é feito pela hidrovia, a diferença do frete de Sorriso até Roterdã passa a ser US\$ 55.11 (US\$ 87.76 - US\$ 32.65)/t se comparado com a opção por Paranaguá e US\$ 36.30 (US\$ 68.95 - US\$ 32.65)/t, se comparado com a opção por Santos.

Para exportar a soja produzida no pólo de Sorriso para Xangai por Paranaguá, o frete rodoviário fica em US\$ 69.76/t e o frete marítimo, em US\$ 36.45/t, totalizando US\$ 106.21/t. Para exportar por Santos, o frete rodoferroviário fica em US\$ 51.20/t e o marítimo, em US\$ 36.45/t, totalizando US\$ 87.65/t. Já a utilização da rodovia BR-163 traria uma redução significativa do custo total do frete para Xangai, e o frete rodoviário até Santarém ficaria em US\$ 43.20/t, e de Santarém até Xangai, US\$ 33.93/t, totalizando US\$ 77,13/t.

A economia gerada pela utilização da BR-163 em relação à Paranaguá e Santos seria, respectivamente, de US\$29.08 (US\$ 106.21 - US\$ 77.13)/t e US\$ 10.52 (US\$ 87.65 - US\$ 77.13)/t. Utilizando a hidrovia dos rios Teles PiresTapajós para exportar para Xangai, o frete rodo-hidroviário ficaria em US\$ 19.60/t e o marítimo, US\$ 33.93/t, totalizando US\$ 53.53/t. 
Comparando com as alternativas de exportar por Paranaguá e por Santos, a opção pela hidrovia traria uma economia de US\$ 52.68 (US\$ 106.21 - US\$ 53.53)/t e US\$ 34.12 (US\$ 87.65 - US\$ 53.53)/t, respectivamente. Se for considerada a utilização do porto do Espadarte, o frete rodo-hidroviário de Sorriso até o referido porto ficaria em US\$28.16/t, e o frete marítimo do porto do Espadarte até Xangai custaria US\$ 10.78/t., totalizando US\$ 38.94/t para transportar uma tonelada de soja do pólo de Sorriso até Xangai utilizando a hidrovia dos rios Teles Pires-Tapajós, saindo pelo porto do Espadarte. Isso geraria uma economia, se comparada às opcõos de Paranaguá e Santos, de US\$ 67.27 (US\$ 106.21 - US\$ 38.94)/t e US\$ 48.71 (US\$ 87.65 - US\$ 38.94)/t, respectivamente.

\subsection{Pólo de Sapezal, MT}

Atualmente, a maior parte da soja produzida no pólo de Sapezal, MT, é exportada pela hidrovia do rio Madeira, tendo que percorrer por rodovia de Sapezal até Porto Velho, RO, e de Porto Velho até Itacoatiara, AM, por hidrovia, onde é embarcada para a exportação. São cerca $900 \mathrm{~km}$ de frete rodoviário a um custo de US\$ 28.80/t e mais $1.056 \mathrm{~km}$ de frete hidroviário que custa US\$ 8.45/t. De Itacoatiara até Roterdã são $8.500 \mathrm{~km}$, cujo frete custa US\$12.75/t. Somados, os fretes rodoviário, hidroviário e marítimo totalizam US\$ 50.00/ t para levar uma tonelada de soja de Sapezal até Roterdã.

Caso a hidrovia dos rios Guaporé-Mamoré-Madeira estivesse funcionando em toda sua extensão, seriam aproximadamente $2.300 \mathrm{~km}$ de hidrovia de Sapezal até Itacoatiara cujo frete ficaria em US\$18.40/t. A distância a ser percorrida por rodovia para chegar à hidrovia seria em torno de $150 \mathrm{~km}$ a um custo de US\$ 4.80/t. Somando-se o frete rodoviário, o hidroviário e o marítimo, custaria em torno de US\$ 35.95/t para se transportar uma tonelada de soja de Sapezal até Roterdã fazendo uso da hidrovia em toda a sua extensão. O Quadro 4 apresenta o esquema de transporte multimodal da soja produzida em Sapezal, MT, até os portos de Roterdã ou Xangai.

Quadro 4 - Custos de transporte multimodal da soja de Sapezal, MT, à Roterdã ou Xangai

\begin{tabular}{|c|c|c|c|c|}
\hline ORIGEM & RODOVIÁRIO & HIDROVIÁRIO & MARÍTIMO & DESTINO \\
\hline \multirow[t]{5}{*}{ Sapezal, MT } & $\begin{array}{c}\text { Porto Velho } \\
\text { US\$ } 28.80\end{array}$ & $\begin{array}{c}\text { Itacoatiara } \\
\text { US\$ } 8.45\end{array}$ & $\begin{array}{c}\text { Roterdã } \\
\text { US\$ } 12.75\end{array}$ & $\begin{array}{c}\text { Roterdã } \\
\text { US\$ } 50.00\end{array}$ \\
\hline & $\begin{array}{c}\text { Santíssima Trindade } \\
\text { US\$ } 4.80\end{array}$ & $\begin{array}{l}\text { Itacoatiara } \\
\text { US\$ } 18.40\end{array}$ & $\begin{array}{c}\text { Roterdã } \\
\text { US\$ } 12.75\end{array}$ & $\begin{array}{c}\text { Roterdã } \\
\text { US\$ } 35.95\end{array}$ \\
\hline & $\begin{array}{l}\text { Porto Velho } \\
\text { US\$ } 28.80\end{array}$ & $\begin{array}{l}\text { Itacoatiara } \\
\text { US } \$ 8.45\end{array}$ & $\begin{array}{c}\text { Xangai } \\
\text { US\$ } 31.65\end{array}$ & $\begin{array}{c}\text { Xangai } \\
\text { US\$ 68,90 }\end{array}$ \\
\hline & $\begin{array}{c}\text { Santíssima Trindade } \\
\text { US\$ } 4.80\end{array}$ & $\begin{array}{l}\text { Itacoatiara } \\
\text { US\$ } 18.40\end{array}$ & $\begin{array}{c}\text { Xangai } \\
\text { US\$ } 31.65\end{array}$ & $\begin{array}{c}\text { Xangai } \\
\text { US } \$ 54.85\end{array}$ \\
\hline & $\begin{array}{c}\text { Santíssima Trindade } \\
\text { US } \$ 47.36\end{array}$ & $\begin{array}{l}\text { Puerto Maldonado } \\
\text { US\$ } 14.24\end{array}$ & $\begin{array}{c}\text { Xangai } \\
\text { US\$ } 8.58\end{array}$ & $\begin{array}{c}\text { Xangai } \\
\text { US\$ } 70.18\end{array}$ \\
\hline
\end{tabular}

Fonte: Resultados da Pesquisa.

Comparando-se a utilização da hidrovia em toda a sua extensão com o atual trajeto rodo-hidroviário, haveria uma redução de custos da ordem de US\$ 14.05/t de soja transportada. 
No caso de exportar para Xangai, pela rota usada atualmente, o custo do frete rodo-hidroviário é o mesmo quando se exporta para Roterdã, ou seja, US\$ 37.25/t, mudando apenas o frete marítimo, pois Xangai está a $21.100 \mathrm{~km}$, cujo frete fica em US\$31.65/t, A soma do frete rodo-hidroviário e do marítimo perfaz um total de US\$ 68.90/t.

Caso fosse possível fazer uso da hidrovia desde o terminal projetado de Vila Bela da Santíssima, MT, no rio Guaporé, para transportar a soja até Itacoatiara, AM, isso ficaria em US\$23.20/t já computado o frete rodoviário de Sapezal até o terminal hidroviário. O frete marítimo de Itacoatiara até Xangai ficaria o mesmo do caso anterior, ou seja, US\$31.65/t, que, somado ao frete rodo-hidroviário, ficaria em US\$ 54,85/t para se transportar uma tonelada de soja de Sapezal até Xangai.

Outra alternativa de escoamento da soja mato-grossense para o mercado externo, especialmente quando o destino é o mercado asiático, é a saída pelo Oceano Pacífico. A alternativa analisada é o uso da hidrovia dos rios GuaporéMamoré-Beni-Madre de Dios até Puerto Maldonado, em território peruano, e seguindo a partir daí de caminhão até o porto de San J uan de Marconda, Peru (esse porto será usado como referência por apresentar condições de atraque de navios Post-Panamax). Quando essa hidrovia estiver funcionando em toda a sua extensão, serão $1.780 \mathrm{~km}$ por hidrovia desde Vila Bela da Santíssima Trindade, MT, até Puerto Maldonado, Peru, cujo frete ficaria em US\$14.24/t, e de Puerto Maldonado até o porto de San J uan de Marconda são $1.330 \mathrm{~km}$ de rodovias, cujo frete fica em US\$ 47.36/t. Do porto San J uan de Marconda ao porto de Xangai são $17.160 \mathrm{~km}$ e o frete ficaria em US\$ 8.58/t. Somando-se os fretes rodoviários, para levar a soja até o terminal hidroviário, o hidroviário, o hidroviário em território peruano e o marítimo, chega-se ao valor de US\$ 70.18/t para se transportar uma tonelada de soja de Sapezal até Xangai saindo pelo Pacífico.

\section{Conclusão}

Neste trabalho de pesquisa sobre a infra-estrutura de transporte para o escoamento da produção de soja do Estado do Mato Grosso, ficou evidenciado que nem só esse Estado, mas o Brasil é extremamente deficiente de infra-estrutura de transporte. A opção pelo modal rodoviário por si só já gera muitas controvérsias, pois um país com dimensões continentais jamais poderia ter feito essa opção, haja vista que é o segundo modal mais caro, só perdendo para o modal aeroviário, indicado para o transporte de produtos com alto valor agregado. Se isso não bastasse, a maioria das estradas brasileiras se encontra em péssimas condições de manutenção, onerando o frete, envelhecendo prematuramente a frota, além de colocar em risco a vida dos usuários.

Nesse sentido, a eficiência dos produtores de soja mato-grossenses não é suficiente para garantir competitividade no mercado externo. Para garantir essa eficiência é necessário que se tenha à disposição uma eficiente infra-estrutura de transporte, que permita que os insumos cheguem com fretes razoáveis e, principalmente, o escoamento do grão produzido sem que se perca a vantagem competitiva perante os concorrentes do mercado externo desta commodity.

Pelas simulações realizadas neste trabalho, verifica-se que é possível o uso da ferrovia em alternativa à rodovia. O modal ferroviário traz economias 
significativas quando comparado ao rodoviário, Fica evidente também que o uso de hidrovias gera grande economia, em função de apresentar o menor frete dentre os três modais de transporte mais utilizados: rodoviário, ferroviário e hidroviário.

Destaca-se, também, o fato de as hidrovias do rio Madeira, dos rios Teles Pires-Tapajós, das Mortes-Araguaia-Tocantins e a rodovia BR-163 serem dirigidas para o Norte, que por si só já representariam vantagem em função dos pólos consumidores de soja estarem localizados no hemisfério Norte, não sendo necessário o produto ser transportado em direção ao Sul, voltando para o Norte após ser exportado pelos portos de Santos ou Paranaguá, como se faz atualmente, aumentando o valor do frete até o destino final.

Outro fator que se deve levar em consideração é o tipo de embarcação para o transporte marítimo, pois navios de grande capacidade de carga (Post-Panamax) reduzem significativamente o valor do frete, ficando em torno de um terço do valor do frete dos navios Panamax, mas, para isso, o país tem que dotar os seus portos de infra-estruturas necessárias para receberem esses navios, de maiores dimensões, inclusive de maiores calados, necessitando aumentar a profundidade dos portos brasileiros utilizados para o embarque da soja.

Pelos cálculos realizados no desenvolvimento deste trabalho, constatou-se que caso se dispusesse de ferrovias, hidrovias e dos portos mencionados, poderia ser gerada uma economia de até US\$ 67.75 por tonelada de soja transportada até o seu destino final, quando comparada com o embarque realizado pelo porto de Paranaguá, como acontece atualmente. O produto brasileiro seria muito mais competitivo no mercado internacional, o que poderia propiciar maiores divisas ao país e melhores remunerações aos agricultores brasileiros.

\section{Referências}

BRASIL - Administração das Hidrovias do Tocantins e Araguaia (AHITAR). Hidrovia Tocantins-Araguaia: solução para o Centro-Oeste e o Centro-Norte. 2005. Disponível em: <http:// www.ahitar.com.br/ site/ modulos/ site2/ hidrovia.php?pagina=Polo_D esenvolvimento>. Acesso em: 14 nov. 2005a.

BRASIL - Administração das Hidrovias do Tocantins e Araguaia (AHITAR). Plano Estratégico de Recursos Hídricos da Bacia dos Rios Tocantins e Araguaia: Relatório do Diagnóstico. Disponível em: $<$ <ttp:// www.ana.gov.br/GestaoRecHidricos/PlanejHidrologico/pbhta/ > Acesso em: 14 nov. 2005b.

BRASIL - AGÊNCIA NACIONAL DE ÁGUAS (ANA). A navegação interior e sua interface com o setor de recursos hídricos. Brasília, 2005. Disponível em: <http:// www.ana.gov.br/ pnrh_novo/documentos>. Acesso em: 19 set. 2005.

BERNARDES, J . A. Novas territorialidades no cerrado mato-grossense. Rio de Janeiro, 2004. Disponível em: <http://www.igeo.uerj.br/VICBG2004/ Eixo5/ e5\%20266.htm>. Acesso em: 20 out. 2005. 
CAMPOS, V. Na contramão do desenvolvimento. 2004. Disponível em: $<\mathrm{http}$ :// www. revistadistribuicao.com.br/ content.asp?page=210\&id_edicao=37>. Acesso em: 6 dez. 2004.

ECONOMIA AGRICULTURA. Oeste vai produzir 2 milhões de toneladas de soja. 2005. Disponível em: <http://www.amazonialegal.com.br/ htm>. Acesso em: 2 out. 2005.

ELETROBRÁS. Complexo hidrelétrico do rio Madeira. 2005. Disponível em: <http:// www.irn. org/pdf/iirsa/ ElectroMadeira_po.pdf>. Acesso em: 1. dez. 2005.

FURNAS CENTRAIS ELÉTRICAS. Inventário do rio Madeira. 2005. Disponível em: <http:// www.abdib.org.br/downloads_geral/furnas.pdf>. Acesso em: 12 maio 2005.

GAMBOA, T. Fôlego verde. 2005. Disponível em: <http:// www.olharvital.ufrj.br/ant/ 2005_09_22>. Acesso em: 20 mar. 2006.

GEIPOT- Empresa Brasileira de Planejamento dos Transportes. 1997. Disponível em: <http:// www.transportes.gov.br/ bit/ferro/ FERRO.htm>. Acesso em: 20 mar. 2006.

GOMES, E. Enfim, asfalto para a BR 158: entendimento garante recursos para trecho da rodovia. Revista RDM, Cuiabá, v. 8, n. 102, p.18-19, maio 2005.

. Mato Grosso nos trilhos: Ferronorte retoma construção da ferrovia para Cuiabá. Revista RDM, Cuiabá, v. 5, n. 65, p.8-10, jul. 2004a. $\overline{5} \overline{8}, \bar{p} . \overline{8}-10$, maio $2004 \mathrm{~b}$.

. O pai da rodovia Cuiabá-Santarém. Revista RDM, Cuiabá, v. 5, n. . Rodofluvial: o melhor caminho: Mato Grosso depende da BR 163 para chegar aos portos do Tapajós. Revista RDM, Cuiabá, v. 5, n. 42, p.12-17, fev. 2004c.

. Um trem para Cuiabá: Ferronorte bota fim às especulações. Revista RDM, Cuiabá, v. 5, n. 69, p.12-15, ago. 2004d.

GONÇALVES, C. W. P. Navegar é preciso; viver não é preciso. Rio de Janeiro, $2000 . \quad$ Disponível em: <http:// www.cibergeo.org/ agbnacional/ documentos/ GONCAVELS.doc>. Acesso em: 3 out. 2005.

MATO GROSSO. Mapa Rodoviário do Mato Grosso. Disponível em: <http:// www.achetudoeregiao.com.br/ MT/ mapa_rodoviario_mato_grosso.htm> Acesso em: mar. 2005.

MELO, F. H. Série agronegócio. 2004. Disponível em: <http:// www.fazendeiro.com.br>. Acesso em: 10 jul. 2004. 
PAULA, S. R de; FAVERET FILHO, P. Panorama do complexo soja. 2005. Disponível em: <http://www.bndes.gov.br/ conhecimento/bnset/ set804.pdf>. Acesso em: 9 ago. 2005.

PAVAN, R. C. Modelo Integrado: O Papel do Operador de Transporte Multimodal Disponível em <http:// www.logistica- es.com.br/ >. Acesso em setembro de 2006.

RIBEIRO, O. BR-163: soja e a Amazônia. Revista RDM, Cuiabá, v. 6, n. 90, p.11, fev. 2005.

. Desfazer o nó antes que seja feito. Revista RDM, Cuiabá, v. 7, n. 136, p. $12-15$, fev. 2006.

$\overline{2} \overline{0} \overline{0} \overline{4}$

. Um sonho do passado. Revista RDM, Cuiabá, v. 5, n. 5, p.16, ago.

RIVA NETO, A. da. Infra-estrutura e logística para o agronegócio. São Paulo, 2004. Seminário 40 anos IPEA. Disponível em: <http:// www.ipea.gov.br/politica/inovacoes/ Logistica.ppt>. Acesso em: 30 ago. 2005.

ROCHA, A. Hidrovias são alternativas mais baratas para o transporte no Mato Grosso. 2004. Disponível em: <http:/ / anba.com.br/ especial.php?id=160>. Acesso em: 22 set. 2005.

SEPLAN-MT-Secretaria de Estado de Planejamento e Coordenação Geral do Estado do Mato Grosso. Anuário estatístico 2002. Cuiabá: SEPLAN-MT, 2002.

WEDEKIN, I. Série agronegócio. 2004. Disponível em: <http:// www.fazendeiro.com.br>. Acesso em: 10 jul. 2004.

ZYLBERSZTAJ N, D.; NETO, M. F. Economia e gestão dos negócios agroalimentares. São Paulo: Pioneira, 2000. 